\title{
Identification of The Phases of The Spread of Covid-19 in Maluku Province with Richards Curve
}

\author{
Nanang Ondi, Francis Y. Rumlawang and Yopi A. Lesnussa
}

\begin{abstract}
Richards Curve is an extension of the Logistics Curve which was first discovered in $\mathbf{1 9 5 9}$ and is a type of sigmoid curve where in the sigmoid curve there are 3 growth phases, namely the logarithmic phase, the linear phase and the aging phase. This research aims to identify and determine the phase of the spread of COVID-19 in Maluku province with the Richards curve. From the calculation results obtained that the initial phase of the spread occurred on March 23 - July 5 2020, the peak phase of the spread occurred on July 6 - October 22 2020, the final phase of the peak of the spread occurred on October 23, 2020 April 14, 2021 and began to enter the final phase of the spread on April 15, 2021.
\end{abstract}

Index Terms-Covid-19, Richards curve, sigmoid curve.

\section{INTRODUCTION}

C ORONAVIRUS is a group of viruses from the subfamily Orthocronavirinae in the Coronaviridae family and the order Nidovirales. This group of viruses can cause disease in birds and mammals, including humans [1] In 2002, the SARS-CoV coronavirus (SARS Coronavirus) caused Severe Acute Respiratory Syndrome (SARS) in Guangdong, China [2]. In 2012 the type of Coronavirus MERS-CoV (MERS Coronavirus) caused Middle Eastern Respiratory Syndrome (MERS) which occurred in Saudi Arabia and the Middle East [3]. On February 11, 2020, WHO inaugurated the term COVID-19 (Coronavirus Disease 2019) which is an infectious disease similar to influenza caused by Severe Acute Respiratory Syndrome 2 (SARS-CoV-2) [4], [5]. The first COVID19 was reported in Indonesia on March 23, 2020, with two cases. Data on March 31, 2020, showed that there were 1,528 confirmed cases and 136 deaths.

On March 23, 2020, the city of Ambon reported the first case of COVID-19 and made Maluku the 20th province in Indonesia with confirmed cases of COVID-19 and on April 27, 2020, the city of Ambon became the only area in Maluku province designated as a red zone for COVID-19 cases namely transmission with high risk, while Buru Island, Central Maluku and West Seram (SBB) are designated as yellow zone areas, namely transmission with low risk, and for Eastern Seram (SBT), Southwest Maluku (MBD), Islands Tanimbar, Aru Islands and Southeast Maluku (MALRA) still have the status of a green zone namely, areas where there are no confirmed cases and on June 22, 2020, with a total of 1212 confirmed cases, the Ambon city government officially implemented the PSBB phase I policy.

The authors are with the Department of Mathematics, Pattimura University, 97233 Indonesia e-mail: nanangondi21@gmail.com, yopi_a_lesnussa@yahoo.com, rumlawang@yahoo.com.

Manuscript received September 26, 2021; accepted October 15, 2021.
In 1959, Richards in his research entitled: A Flexible Growth Function For Empirical Use first introduced the Richards Curve [6] or can be called the Generalized Logistics Curve [7] where the Richards curve is a model of the population growth curve, under conditions where growth is not symmetrical with the inflection point [8], [9], and is a type of sigmoid curve [10] where the sigmoid curve or growth curve [11] is a curve that characterizes the pattern of plant growth [12] with a growth pattern shaped like the letter $\mathrm{S}$ [13] i.e. plant growth is slow at first then gradually faster until the maximum point is reached and in the end the growth rate decreases or in other words there are 3 main phases in growth on the sigmoid curve, namely the logarithmic phase, linear phase and aging phase [14] where the linear phase can be divided into 2 phases, namely the growth phase and the maturing phase [15].

In May 2020, Yuri Tani Utsunomiya in a study entitled "Growth Rate And Acceleration Analysis Of The COVID19 Pandemic Reveals The Effect Of Public Health Measure In Real Time" used the Gompertz Curve which is one type of sigmoid curve and identified the phases the spread of COVID19 cases in China, South Korea and Austria, namely the initial spread phase, the phase when rapid growth occurs, the phase where there are already applicable measures and the final phase, which is when the spread of COVID-19 cases can be controlled.

\section{Materials AND MethodS}

This study uses data on cumulative cases of COVID-19 in Maluku province from March 23 - November 4, 2020 and estimates are made with Richards Function parameters, using the Python 3.6 programming language namely [16]:

$$
I(t)=\left(\frac{K}{\left[1+a e^{-k\left(t-t_{m}\right)}\right]^{\frac{1}{a}}}\right)
$$

where $I(t)$ is the population size or the total number of cases that occurred at the time of $t, K$ is the carrying capacity or total of the latest cases, $k$ is the rate of growth of cases, $t_{m}$ is the inflexion point or time of the peak of the spread of COVID-19 cases. From the estimation results, it can be obtained Richards Curve where the phases of the Richards Curve can be described in Figure 1.

With the steps for the distribution of assets on the Richards Curve, it can be described in the flow chart as in Figure 2. 


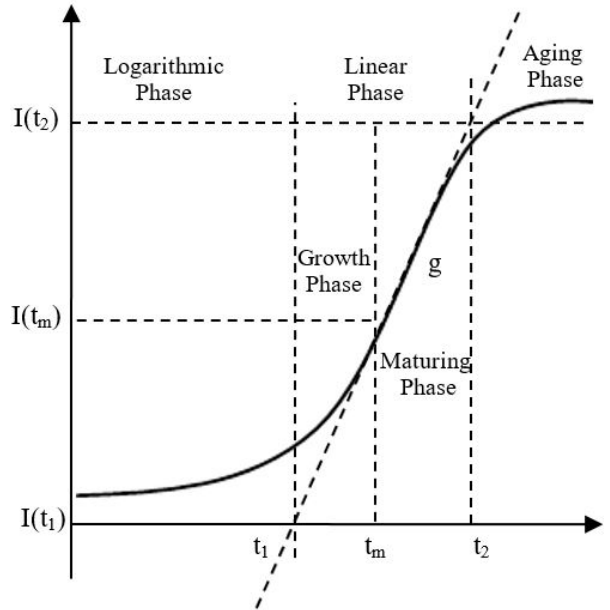

Fig. 1. Phase division on the Richards Curve [17], [18], [19].

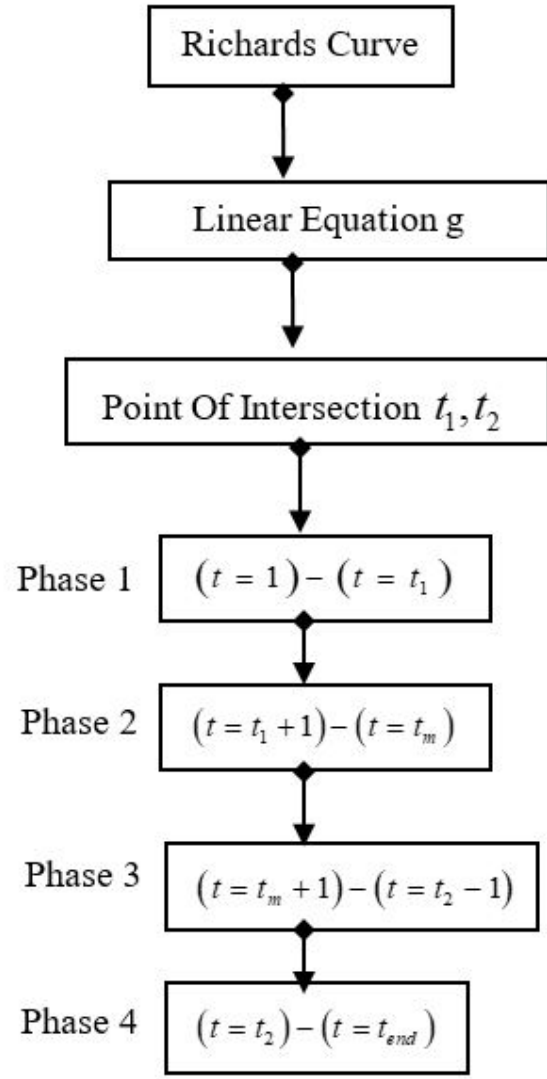

Fig. 2. Phase division flowchart on the Richards Curve.

\section{Results AND Discussions}

The deployment phase is divided into 4 phases where the first step is to find the equation of the line $g$ that best fits the Richards curve. From the result of curve fitting, Richards equation is obtained, namely:

$$
I(t)=\left(\frac{9451.245}{\left[1+0.085 e^{-0.01(t-213.918)}\right]^{\frac{1}{0.085}}}\right)
$$

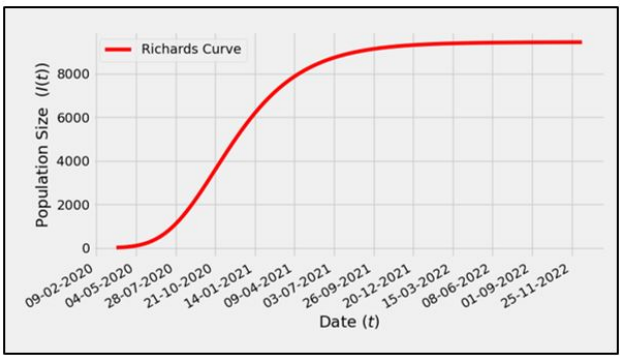

Fig. 3. Richards Curve.

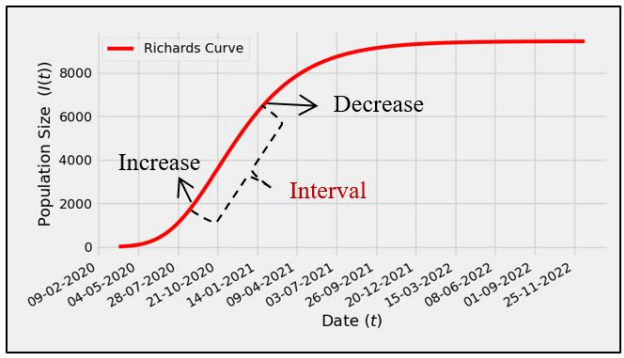

Fig. 4. $t$-value interval on the Richards Curve.

So that the Richards Curve can be described in Figure 3. Where is known the inflection point or $\left(t_{m}, I\left(t_{m}\right)\right)$ of the Richards Curve in the Figure 3 is $(214, I(214))$. The steps to find the equation of the line $g$ are as follows:

1) Choose the $t$-value interval on the Richards Curve with $t_{m}$ as the middle value for the interval. What should be noted is that the $t$-value interval is chosen by looking back at the Richards Curve in Figure 3, which is choosing the approximate $t$-value when the Richards Curve begins to increase up to the $t$-value when the Richards Curve begins to decrease or can be described in Figure 4.

Then the $t$-value interval is chosen, namely $[209,219]$.

2) Substitute all the values of the points $\left(t_{i}, I\left(t_{i}\right)\right)$ and from the selected interval $t$, namely $[209,219]$ with $t_{i}<t_{j}$ into the equation of the line [20]:

$$
I(t)_{l i n}=\left(\frac{I\left(t_{j}\right)-I\left(t_{i}\right)}{t_{j}-t_{i}}\right) t+\left(\frac{t_{j} I\left(t_{i}\right)-t_{i} I\left(t_{j}\right)}{t_{j}-t_{i}}\right)
$$

3) Calculate and compare the RMSE values of all point values $\left(t_{i}, I\left(t_{i}\right)\right)$ and $\left(t_{j}, I\left(t_{j}\right)\right)$ in the equation of the line $I(t)$ with point values on the Richards Curve for $209 \leq t \leq 219$.

4) Selecting the points $\left(t_{i}, I\left(t_{i}\right)\right)$ and $\left(t_{j}, I\left(t_{j}\right)\right)$ which produces the smallest RMSE value, which is the smallest RMSE obtained is 0.01230385 at the point $\left(t_{i}, I\left(t_{i}\right)\right)=$ $(214, I(214))$ and $\left(t_{j}, I\left(t_{j}\right)\right)=(218, I(218))$. So from Equation (2), the equation of the line $g$ is obtained, namely:

$$
\begin{aligned}
I(t)_{l i n} & =\left(\frac{I(218)-I(214)}{218-214}\right) t+\left(\frac{218 I(214)-214 I(218)}{218-214}\right) \\
& =33.34992209 t-3514.228963
\end{aligned}
$$

Where from Figure 2, the point of intersection between the line $\left(t_{2}\right)$ and the line $I\left(t_{1}\right)$ is the limit of the 


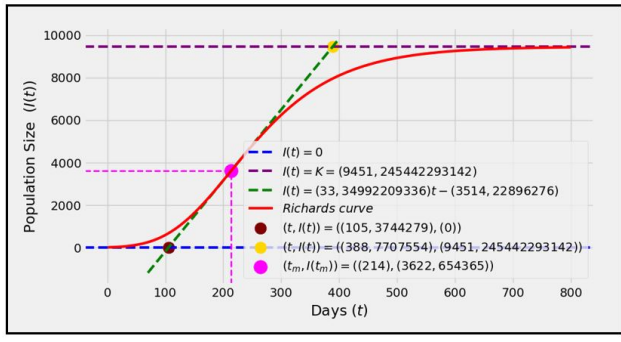

Fig. 5. Calculation result for deployment phase classification.

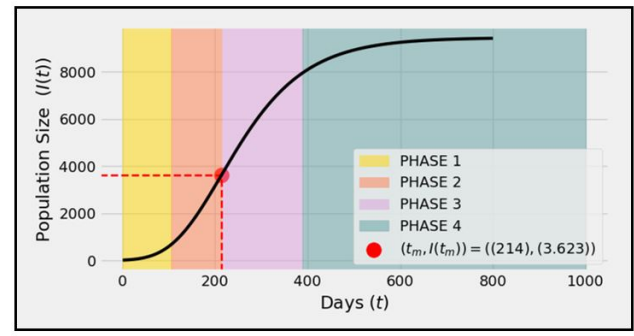

Fig. 6. The phase of the spread of covid-19 in Maluku province from the estimation results.

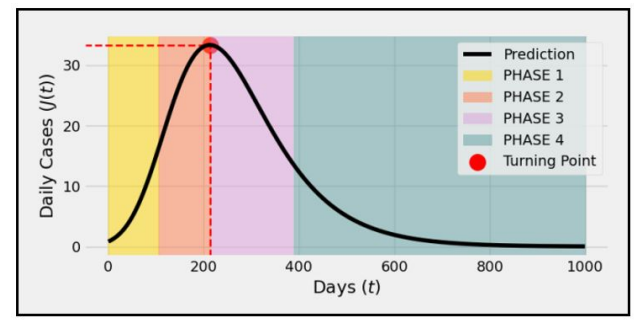

Fig. 7. The phase of the spread of covid-19 in Maluku province from the daily case addition curve.

occurrence of the first phase, namely the initial spread phase, and the point of intersection between the line $\left(t_{2}\right)$ and the line $I\left(t_{2}\right)$ is the initial time of the occurrence of the last phase, namely the final phase of the spread, while the second phase occurs until the point of inflection on the curve where from calculation results can be described in Figure 5.

So from the calculation results it can be concluded that the first phase occurs at $t=1$ to $t=105$ the second phase occurs at $t=106$ until the turning point, namely at $t=214$, the third phase occurs at $t=215$ to $t=388$ and the last phase, namely the fourth phase, occurred at $t=389$ to $t=1159$, then the next phase of the spread of COVID-19 cases in Maluku province on the Richards Curve can be described in Figure 6

Or it can be described as the distribution phase on the prediction result curve for the addition of daily cases from the Richards Curve, which is displayed in Figure 7.

\section{A. First Phase}

The initial spread phase of COVID-19 cases in Maluku province occurred on March 23 - July 5, 2020 or for 105

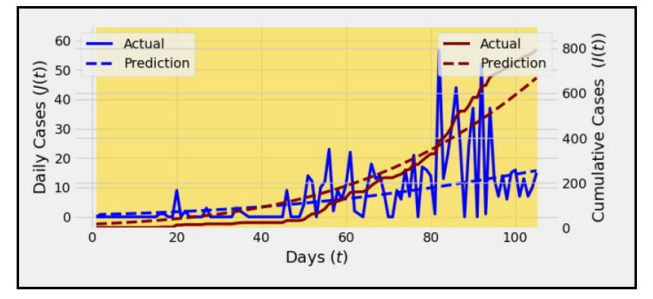

Fig. 8. Comparison of cumulative cases and daily cases in the early dissemination phase.

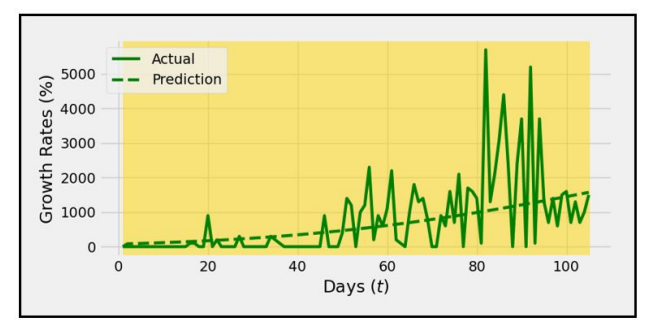

Fig. 9. Comparison of the daily growth rate in the early deployment phase.

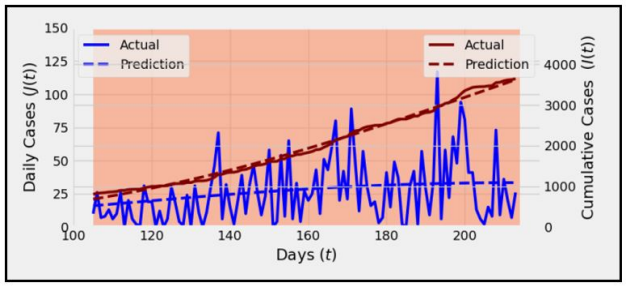

Fig. 10. Comparison of cumulative cases and daily cases at the peak of the spread.

days with an average daily addition of 8 cases and a growth rate of $755.23 \%$, while based on the estimation results the initial phase occurred with an average the average daily case addition was 6 cases and the growth rate was $620.581 \%$ with the total cumulative cases at the end of the phase being 668 cases. Comparison of cumulative cases, daily case increase and growth rate in this phase can be described in Figure 8 and Figure 9.

\section{B. Peak Deployment Phase}

The peak phase of the spread began after the PSBB phase 1 in Ambon city ended, namely on July 5, 2020, in this phase the average daily addition of cases increased to 26 cases with the average growth rate increasing significantly as much as $1864.945 \%$ from the initial spread phase, namely to $2620.183 \%$ while based on the estimation results the second phase occurred with an average daily addition of 27 cases and a growth rate of $2710.449 \%$. Comparison of cumulative cases, daily case increase and growth rate in this phase can be described in Figure 10 and Figure 11.

\section{The Final Phase of Peak Spread}

After the peak of the spread, on October 23 with a total of 3718 confirmed cases, the spread of COVID-19 in Maluku province entered the final phase of the peak of the spread. In 


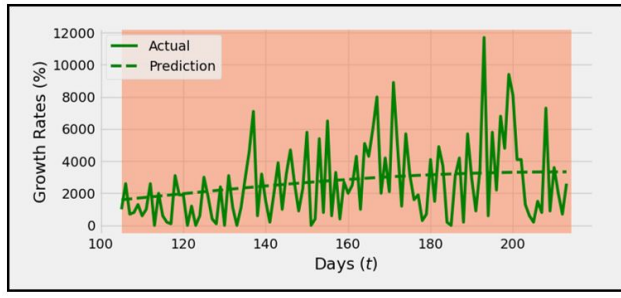

Fig. 11. Comparison daily growth rate at peak phase of spread.

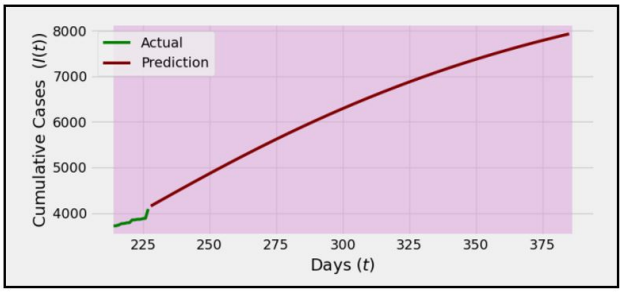

Fig. 12. Progression of cumulative cases in the phase after the peak of the spread.

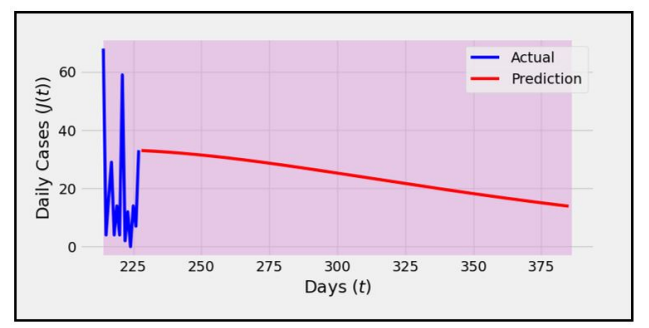

Fig. 13. Daily case development in the phase after the peak of the spread.

this phase, the average daily addition of cases is predicted to be 24 cases and the average growth rate is predicted to decrease by $252.3578 \%$ from the previous phase, which is $2367.826 \%$ with cumulative case growth and daily cases in this phase can be described in Figure 12 and Figure 13.

In Figure 11, it can be seen that in the time interval between $t=215$ to $t=227$ or on October 23 - November 4, 2020 which is the deadline for data collection, there is a pattern of decline in cases so that the prediction results, namely at interval $t>227$ are also predicted to be the same thing happened, namely a pattern of decreasing cases for the addition of daily COVID-19 cases and based on the prediction results, this phase occurred for 173 days, namely until April 13, 2021 with a total cumulative case at the end of the predicted phase as many as 7927 cases and for the growth rate in the second phase. The same pattern also occurs, with the percentage starting to decrease until the end of the phase or can be described in Figure 14.

\section{Final Phase of Deployment}

The final phase of the spread of COVID-19 cases in Maluku province is predicted to start on April 15, 2021. In this phase the addition of daily cases has slowed considerably, with a daily average of 2 cases with a growth rate of only $195.7566 \%$. Prediction of cumulative case development, daily addition of

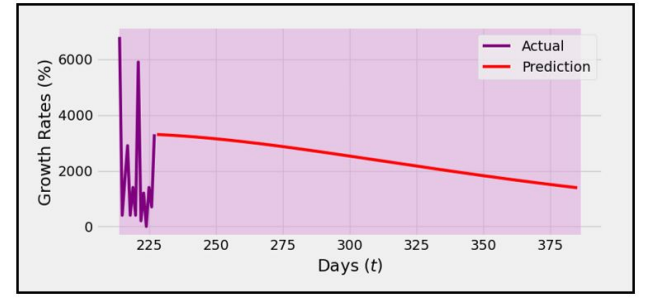

Fig. 14. Daily growth rate in the phase after the peak of the spread.

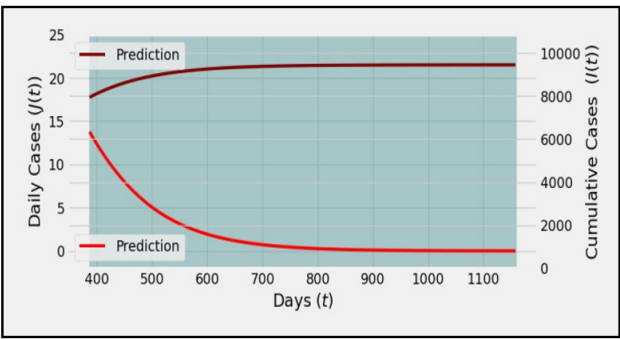

Fig. 15. Progress of cumulative cases and daily cases in the final phase of the spread.

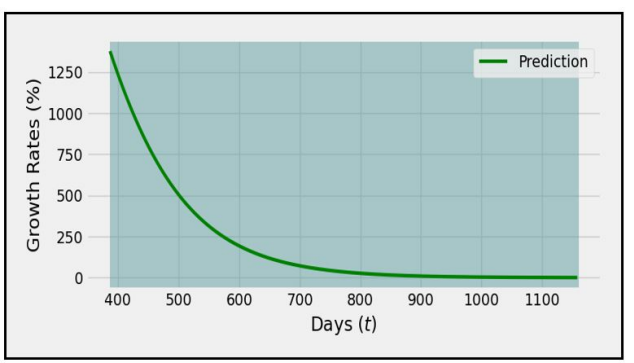

Fig. 16. Daily growth rate in late phase of deployment.

cases and growth rate in the final phase of the spread can be described in Figure 15.

The final phase of the spread occurred with a predicted initial case of 7955 cases or in other words only an increase of 28 cases from the previous phase. Until June 1, 2021, the average daily addition of cases is predicted to be 11 cases per day, with the last cumulative total of cases being $1129.784 \%$ and a growth rate of $1129.784 \%$ and until November 12, 2021, it is predicted that the average daily addition of cases will decrease to 6 cases per day with The last cumulative total cases were 1600 cases and the growth rate fell to $619.4929 \%$. On April 30, 2022 total cumulative cases are predicted to be 9,415 cases with a growth rate of $386.7172 \%$ and until the end of December 2022 the average daily addition of cases is only 2 cases per day with a growth rate of only $240.7123 \%$. This phase ends on May 25, 2023 with a predicted total of 9451 cases and the daily growth rate in this phase can be described in Figure 16.

\section{CONCLuSions}

The initial spread phase of COVID-19 cases in Maluku Province occurred on March 23 - July 5, 2020 with a total cumulative case of 688 cases at the end of the phase, then the spread of COVID-19 cases in Maluku Province entered 
the peak phase on July 6 - October 22, 2020 with a total Cumulative cases at the end of the phase were 3,623 cases and on 23 October 2020 - 14 April 2021 the spread of COVID-19 cases in Maluku province entered the final phase of the peak of the spread with a total predicted cumulative case of 7941 cases and on 15 April 2021, Maluku province is predicted to enter the phase the end of the spread of COVID-19 cases, which is until May 25, 2023 with a total cumulative case of 9.451 cases at the end of the phase.

\section{REFERENCES}

[1] N. Yunus and A. Rezki, "Kebijakan pemberlakuan lock down sebagai antisipasi penyebaran corona virus covid-19," Salam: Jurnal Sosial dan Budaya Syar-i, vol. 7, no. 3, pp. 227-238, 2020.

[2] J. Peiris, S. Lai, L. Poon, Y. Guan, L. Yam, W. Lim, J. Nicholls, W. Yee, W. Yan, M. Cheung, V. Cheng, K. Chan, D. Tsang, R. Yung, T. Ng, and $\mathrm{K}$. Yuen, "Coronavirus as a possible cause of severe acute respiratory syndrome," The Lancet, vol. 361, no. 9366, pp. 1319-1325, 2003.

[3] A. Zumla, D. Hui, and S. Perlman, "Middle east respiratory syndrome," The Lancet, vol. 386, no. 9997, pp. 995-1007, 2015.

[4] C. S. G. of the International et al., "The species severe acute respiratory syndrome-related coronavirus: classifying 2019-ncov and naming it sarscov-2," Nature microbiology, vol. 5, no. 4, p. 536, 2020.

[5] L. Lin, L. Lu, W. Cao, and T. Li, "Hypothesis for potential pathogenesis of sars-cov-2 infection-a review of immune changes in patients with viral pneumonia," Emerging microbes \& infections, vol. 9, no. 1, pp. 727-732, 2020.

[6] F. Richards, "A flexible growth function for empirical use," Journal of experimental Botany, vol. 10, no. 2, pp. 290-301, 1959.

[7] J. Nelder, "182. note: An alternative form of a generalized logistic equation," Biometrics, vol. 18, no. 4, pp. 614-616, 1962.

[8] G. Seber and C. Wild, Nonlinear regression. New Jersey: John Wiley \& Sons, 2003.

[9] H. Anton, Calculus with Analytic Geometry. Wiley, 1980.

[10] C. Imai, H. Sakai, K. Katsura, W. Honto, and Y. Hida, "Growth model for the endangered cyprinid fish tribolodon nakamurai based on otolith analyses," Fisheries science, vol. 68, no. 4, pp. 843-848, 2002.

[11] J. Sachs, Über das Wachsthum! der Haupt-und Nebenwurzeln, 1872.

[12] F. Nugraheni, S. Haryanti, and E. Prihastanti, "Pengaruh perbedaan kedalaman tanam dan volume air terhadap perkecambahan dan pertumbuhan benih sorgum (sorghum bicolor (1.) moench)," Buletin Anatomi dan Fisiologi (Bulletin of Anatomy and Physiology), vol. 3, no. 2, pp. 223-232, 2019.

[13] W. Wahyudi and P. Pamoengkas, "Model pertumbuhan diameter tanaman jabon (anthocephallus cadamba)," Bionatura, vol. 15, no. 1, 2013.

[14] F. Salisbury and C. Ross, Fisiologi tumbuhan. Penerbit ITB, 1995.

[15] L. Gitman and C. McDaniel, Introduction to Business. OpenStax, 2018.

[16] Y.-H. Hsieh, "Richards model: a simple procedure for real-time prediction of outbreak severity," in Modeling and dynamics of infectious diseases, 2009, pp. 216-236.

[17] W. Grzebisz and R. Łukowiak, "Nitrogen gap amelioration is a core for sustainable intensification of agriculture-a concept," Agronomy, vol. 11, no. 3 , p. 419, 2021.

[18] Z. Pödör, M. Manninger, and L. Jereb, "Application of sigmoid models for growth investigations of forest trees," in Advanced Computational Methods for Knowledge Engineering, 2014, pp. 353-364.

[19] S. Shoffner and S. Schnell, "Estimation of the lag time in a subsequent monomer addition model for fibril elongation," Physical Chemistry Chemical Physics, vol. 18, no. 31, pp. 21 259-21 268, 2016.

[20] D. Nuharini, T. Wahyuni, and Indratno, Matematika Konsep dan Aplikasinya: untuk SMP/MTs Kelas VIII. Pusat Perbukuan, Departemen Pendidikan Nasional, 2008. 